\title{
On the Motions of Four Pagoda Clocks in the Forbidden City
}

\section{Yezhuo 李晔卓, 1 CHEN Yu-Hsun 陈羽薰, ${ }^{2}$ YAN Hong-Sen 颜鸿森 ${ }^{3}$}

(1. School of Mechanical, Electronic and Control Engineering, Beijing Jiaotong University, Beijing 100044; 2. Department of Mechanical Engineering, Taiwan University of Science and Technology, Taipei 10607; 3. Department of Mechanical Engineering, Cheng Kung University, Tainan 70101)

\begin{abstract}
Ancient mechanical clocks and automatons are solid evidence regarding the evolution of technological development. At least four ingenious eighteenth-century clocks with pagoda automatons are preserved in the Palace Museum in Beijing. Two were made in China, the other two in Britain. Although the internal mechanical components were maintained and recorded in the late twentieth century, their mechanism structure is mostly not made available to the public owing to the historical value of these artefacts. This study introduces feasible mechanism structures for the four pagoda automatons based on published works, along with considerations of mechanical design. Five subsystems of the clocks are analyzed, and two mechanisms of the pagoda automaton are illustrated. In particular, feasible mechanisms of the four pagoda automatons for raising their stories are explained. The analysis procedure presented in this paper expands the feasibility of reconstruction work on ancient mechanisms with unknown structures.
\end{abstract}

Keywords: pagoda clock, mechanism, automaton, history of machines, Forbidden City

\section{Introduction}

$\mathrm{n}$ automaton is defined as a mechanical device that is capable of achieving a
automatic movable puppet (Rocci, Russo, and Russo 2009; Chen, Ceccarelli, and Yan
2018). Appearing in various forms such as moving animals, blossoming flowers,

Received: November 23, 2020. Revised: December 22, 2020.

1. Research interests: Mechanism design, history of mechanism and machine science, and design of ground mobile robots. Email: li_yezhuo@bjtu.edu.cn

2 Research interests: Mechanism design and history of mechanism and machine science. Email: yhchen@mail.ntust.edu.tw

3 Research interests: Creative designs of modern mechanisms and reconstruction designs of ancient mechanisms. Email: hsyan@mail.ncku.edu.tw 
dancing humanoids, and transforming scenes, mechanical puppets performed for the purpose of entertainment. During the seventeenth to nineteenth centuries, a large number of automatons were made in Europe and exported to many countries, including China (Guan 2007).

In the seventeenth century, European missionaries went to China and introduced clocks with automatons to Chinese emperors in exchange for permission for residence and preaching. These ingenious mechanical automatons were well received by the emperors. In the eighteenth century, a clock workshop was set up in the palace in the Forbidden City to maintain, modify, and manufacture clocks and automatons with local craftsmen, under the guidance of Jesuit missionaries and Western technicians (Guan 2007; Pagani 2001; Guo 2013; Chen 1984; Zhang 1995; Li 2009, 9-37; Hou 2011; Dai 2004). Much literature in that period recorded functions and mechanical structure, for example works by Emperor Kangxi (Aisin Gioro 1711) and the astronomer Xu (1809). Therefore, Chinese-style architecture, decoration, symbols of myths, and folk rituals were also incorporated into these clocks under the emperors' instructions. Later, when the aristocracy and wealthy merchants also became collectors, the clock industry was developed not only in Beijing, but in harbor cities, such as Guangzhou and Suzhou, which facilitated access to imported clocks (Hou 2011; Dai 2004). The timepiece industry in China started in the seventeenth century, reached its height in the eighteenth century, and decayed in the nineteenth century because of the decline of the imperial dynasty. Moreover, the imperial palace was transformed into a museum in 1925, with thousands of mechanical clocks and watches preserved, and the clock workshop remained as a maintenance organization (Guan 2007; Wang, Qin, and Qi 2008). Clocks with a telescopic pagoda that rises in height and returns to its initial position are a typical type of collection held by the Palace Museum in Beijing. According to Guan (2007), Yun and Qin (2003), Lang and Qin (2002), and Qin (2007), there are at least four preserved clocks with pagoda automatons (Figures 1.1-1.4). Initially the stories of each pagoda automaton are telescopically folded inside the lowest one. When its clockwork spring is wound up and switched on, the stories lift one by one, with a musical accompaniment, and return to the original position at the end of the performance. All four of these pagoda clocks were made in the eighteenth century, two of them in Britain and the other two in China (Table 1).

Although the internal mechanical components of the four clocks were maintained and recorded in the late twentieth century, the clocks are mostly not made available to the public owing to their historical value. However, the relevant records (Guan 2007; Guo 2013; Yun and Qin 2003; Lang and Qin 2002; Qin 2007) were published in recent decades with text descriptions about how the automatons work to achieve their performance motions. This paper focuses on the reconstruction work of the pagoda clocks preserved in the Forbidden City from the viewpoint of mechanical design. 
Although these clocks were made in the eighteenth century, the mechanisms arranged to achieve the specific motion are similar to their applications in modern times. This study expands the analysis of history, culture, and technology, and a method of procedural investigation is presented. For ancient mechanical clocks with unknown internal structure, the most feasible mechanisms can be summarized according to the relevant records.

Table 1: Basic data of the four clocks with pagoda automatons*

\begin{tabular}{cccccc}
\hline No. & Name & Date & Origin & $\begin{array}{c}\text { Size }(\mathrm{cm}) \\
\text { (height/length/width) }\end{array}$ & $\begin{array}{c}\text { Mechanical } \\
\text { components }\end{array}$ \\
\hline 1 & $\begin{array}{c}\text { Guard pagoda } \\
\text { clock }\end{array}$ & 1780 & Britain & $95 / 46 / 46$ & $\begin{array}{c}\text { Sprocket, chain, rack, } \\
\text { and pinion }\end{array}$ \\
\hline 2 & Cock pagoda clock & Eighteenth century & $\begin{array}{c}\text { Britain } \\
\text { (James Cox) }\end{array}$ & $244 / 102 / 90$ & $\begin{array}{c}\text { Cam, sprocket, and } \\
\text { chain }\end{array}$ \\
\hline 3 & $\begin{array}{c}\text { Movable pagoda } \\
\text { clock }\end{array}$ & $\begin{array}{c}\text { Qianlong period } \\
(1735-1796)\end{array}$ & Guangzhou, China & $111 / 47 / 47$ & $\begin{array}{c}\text { Linkage, geartrain, } \\
\text { sprocket, and chain }\end{array}$ \\
\hline 4 & $\begin{array}{c}\text { Inlaid enamel } \\
\text { longevity clock }\end{array}$ & $\begin{array}{c}\text { Qianlong period } \\
(1735-1796)\end{array}$ & Guangzhou, China & $108 / 45 / 38$ & Linkage \\
\hline
\end{tabular}

\section{Mechanisms and machines}

To clarify their inner workings from the viewpoint of mechanical engineering, these clocks with automatons can be analyzed via five subsystems, namely power source, transmission, timekeeping device, music generator, and automaton puppets (Yun and Qin 2003; Andrewes 2002; Chen and Yan 2016; Chen et al. 2017a; Chen et al. 2017b). Figure 2 shows the power flow in the five subsystems. Figure 3 illustrates the various mechanisms of the clocks. The power source is a clockwork spring (Figure 3.1). Its elastic energy is transformed into a continuous rotation through a wheel or a reel. Moreover, the power generated by the spring can be adjusted into a regular torque output through a fusee device. The transmission system is mainly used to deliver the power, to adjust the motion speed, and to change the direction or motion type from the input motion (Figure 3.2). The core of a timekeeping device is an escapement, as also shown in Figure 3.2. With a pendulum, the escapement wheel rotates a specific small angle in each swing, causing a regularized output rotation of the hands on the dial. Figure 3.3 shows two types of music generator. Composed of a pinned cylinder and a set of bells/music comb, the music generator is capable of playing a melody. Finally, the mechanical puppets are the subsystem for performing with various automatons, and the mechanism of a posturing puppet is shown in Figure 3.4.

*Sources: Data from Guan (2007); Yun and Qin (2003); Lang and Qin (2002). 


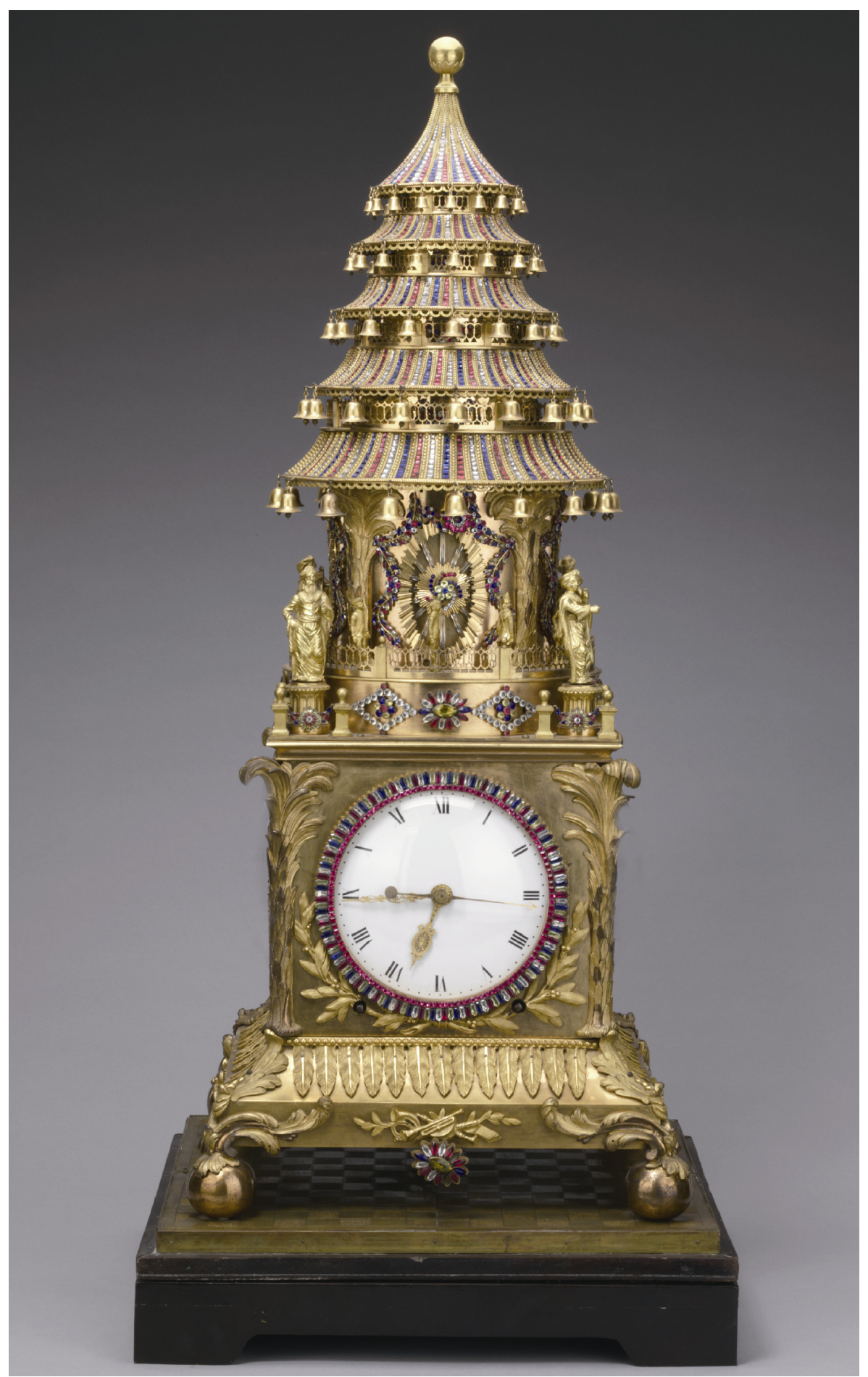

Figure 1: Pagoda clocks in the Forbidden City.

Figure 1.1: Guard pagoda clock (courtesy of the Palace Museum). 


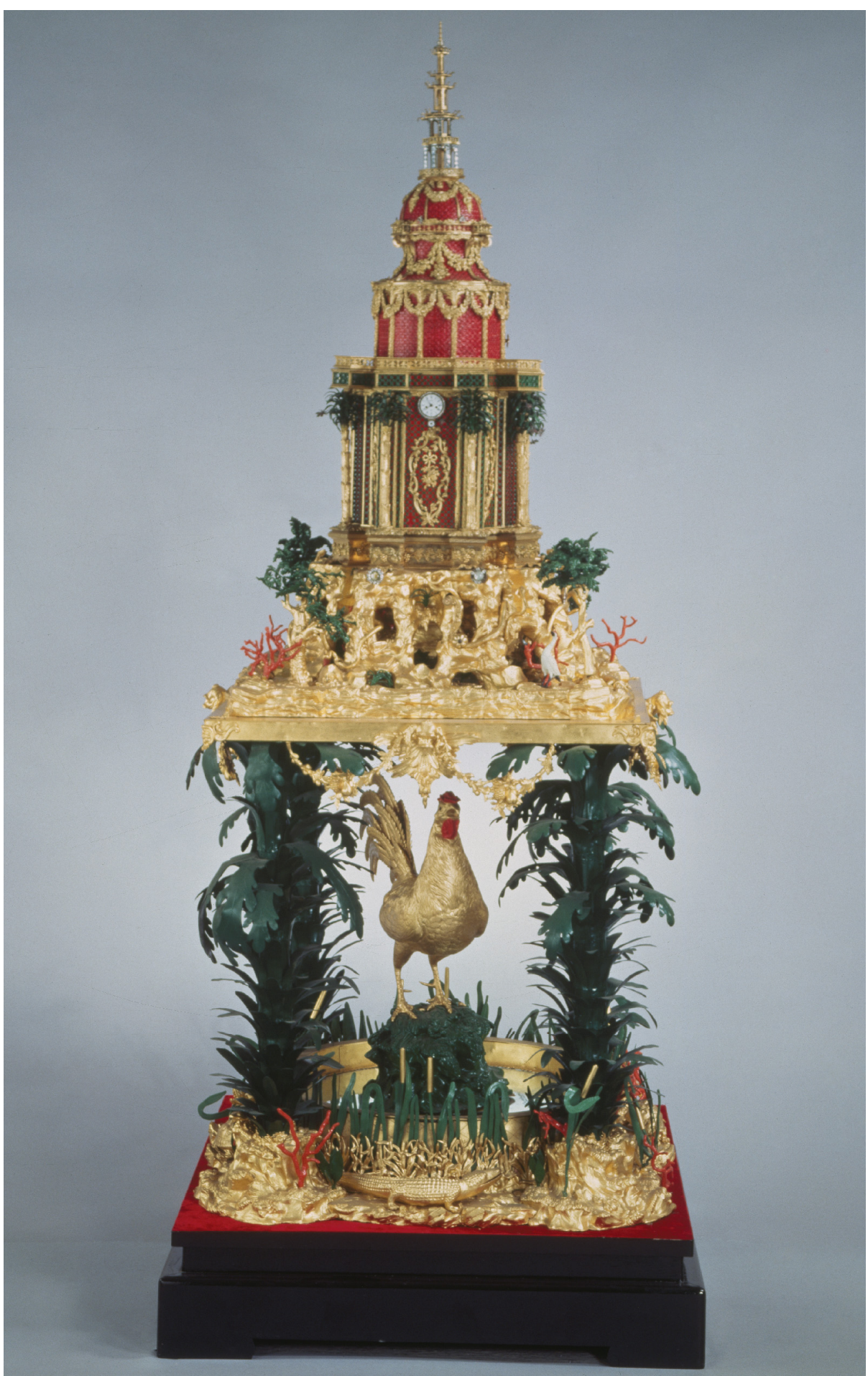

Figure 1.2: Cock pagoda clock (courtesy of the Palace Museum). 


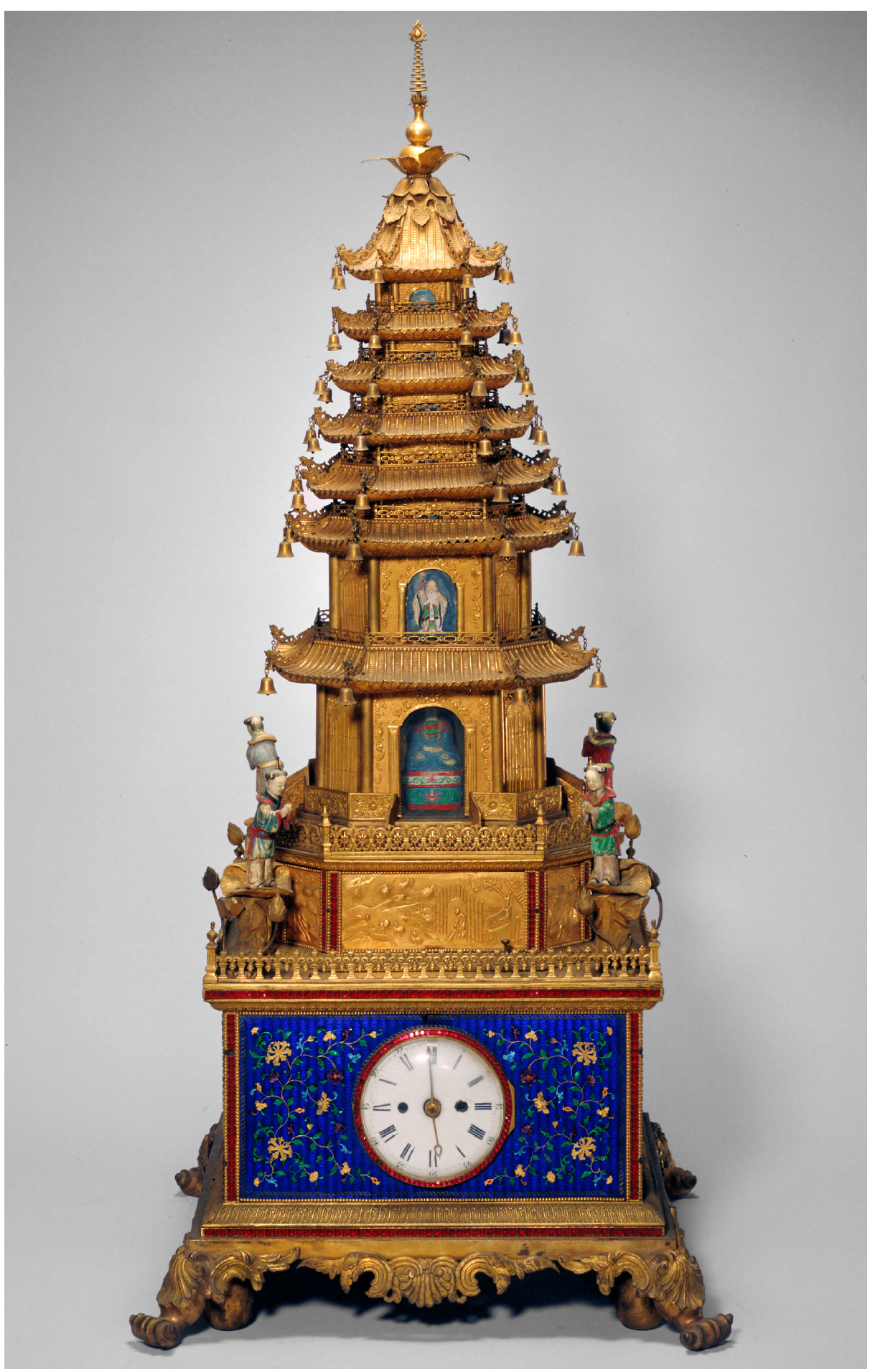

Figure 1.3: Movable pagoda clock (courtesy of the Palace Museum). 


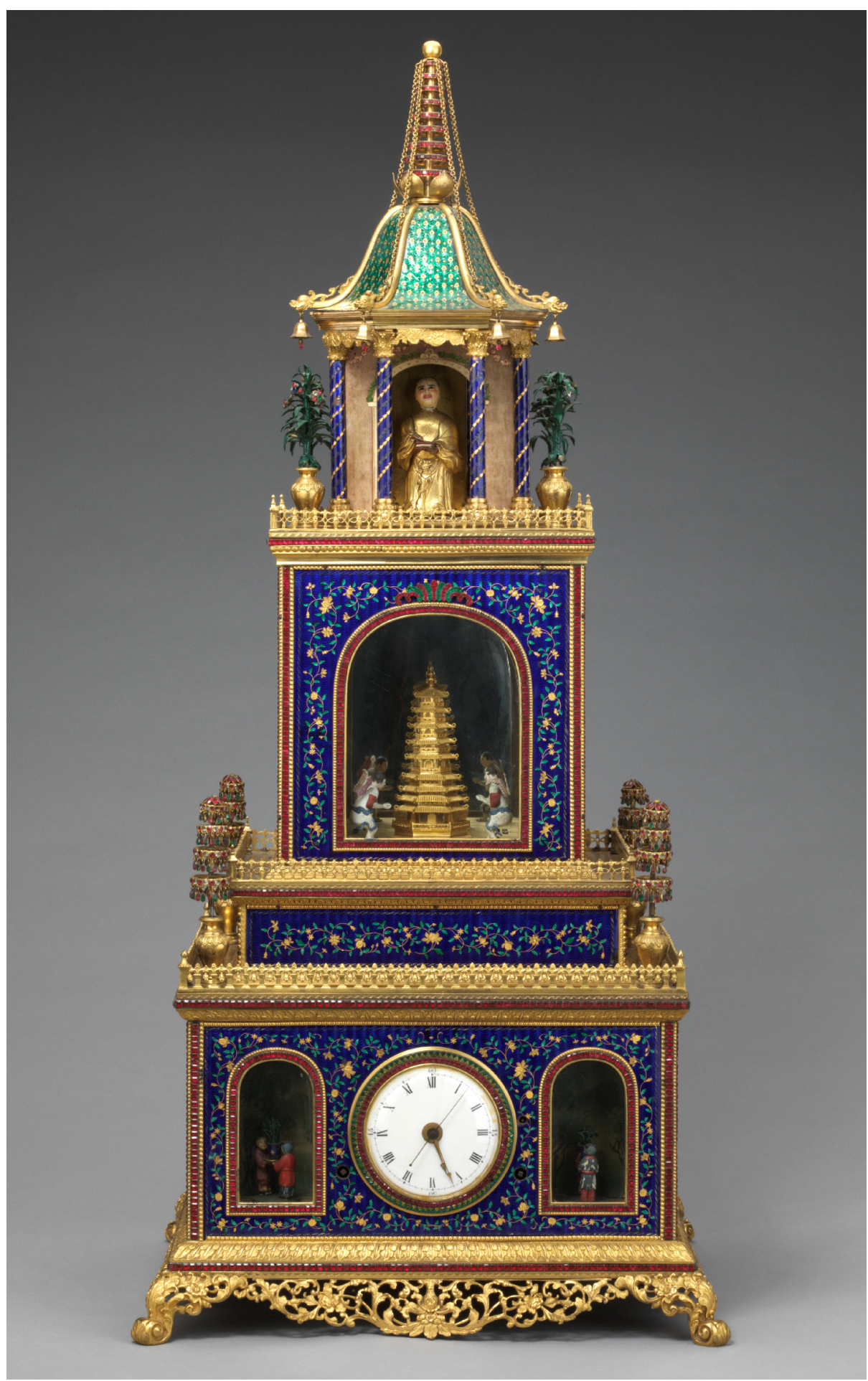

Figure 1.4: Inlaid enamel longevity clock (courtesy of the Palace Museum). 


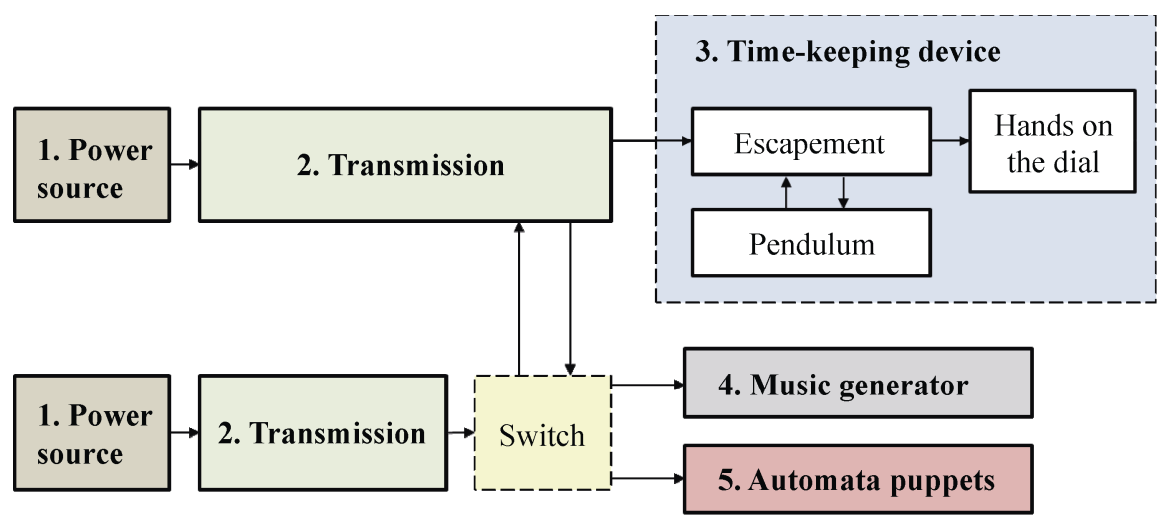

Figure 2: Power flow of the five subsystems.
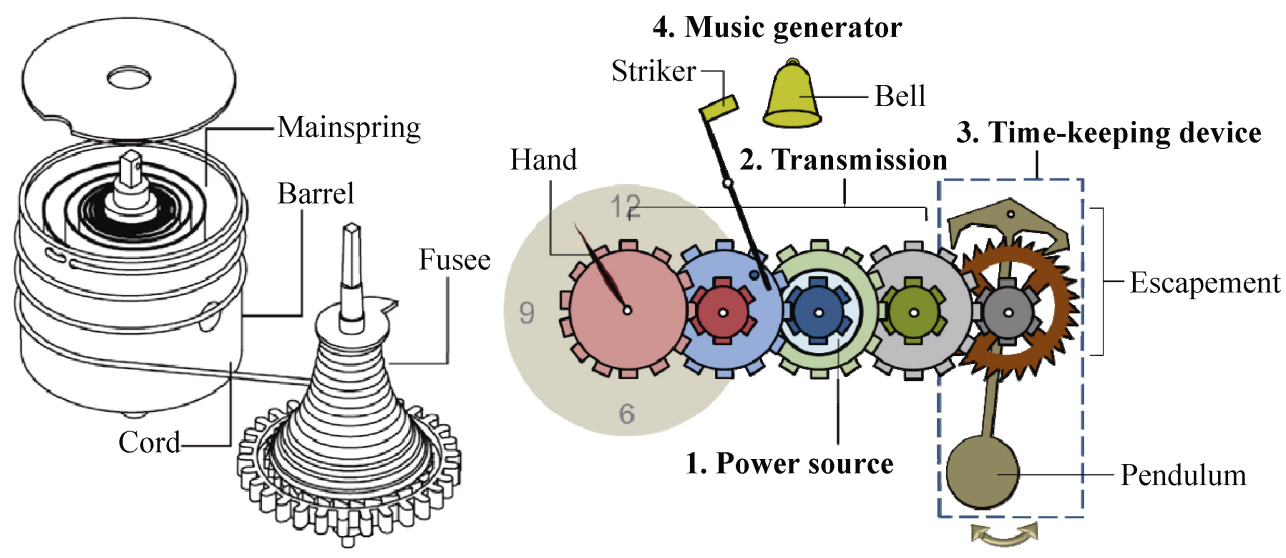

Figure 3: Illustrations of the mechanism structure in a clock.

Figure 3.1: A clockwork spring used as the power source (Andrewes 2002).

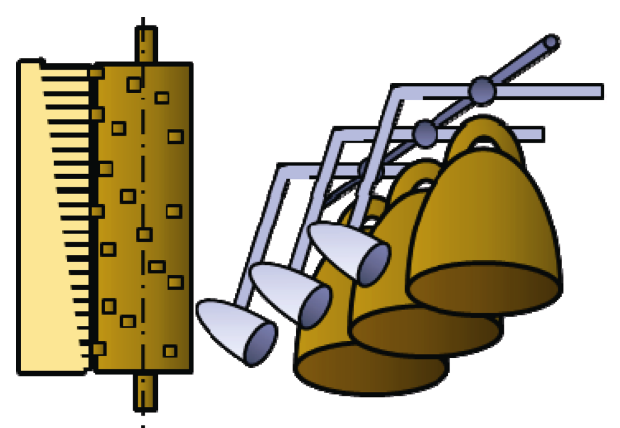

Figure 3.3: Two types of music generator (Chen and Yan 2016).
Figure 3.2: A geartrain in a transmission subsystem and an escapement in a timekeeping device.

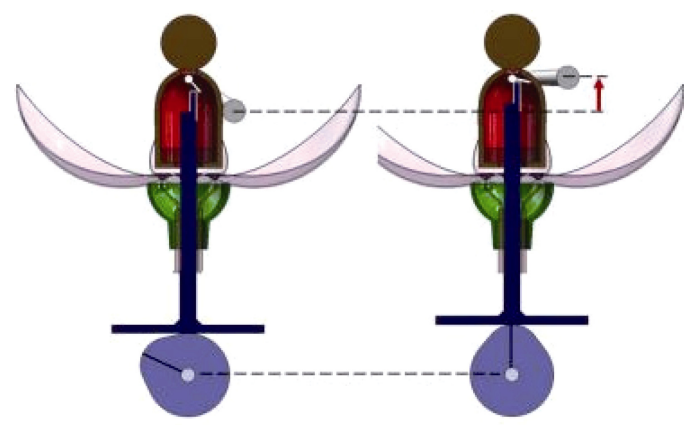

Figure 3.4: An example of mechanical figures in the puppet subsystem (Chen and Yan 2016). 
Among the five subsystems, the automaton puppet is the most complex part, with a great diversity of clock mechanisms. Accordingly, the pagoda automaton in this subsystem is taken as an illustrative example to explain the feasible mechanisms through analyzing the descriptions in available literature.

Moreover, a mechanism is an assembly of the machine's constituent parts (such as links, sliders, rollers, cams, gears, wheels, belts, ropes, chains, and springs) connected by joints (such as revolute, sliding, rolling, cam, gear, and wrapping joints) in a specific manner such that the motion of one or more members can drive the other members to generate prescribed motions (such as continuous, intermittent, reciprocating, and oscillating motions) (Yan 2016).

In order to explain the motions of automaton puppets, some typical mechanisms are outlined below and illustrated in Figure 4.

\subsection{Geartrain}

A gear is a machine component with teeth of appropriate shapes. A mechanism consisting of gears (geartrain) to maintain constant velocity ratio between the input and output gears is called a gear mechanism. It provides rotating motion from one rotating shaft to another by means of successively engaging teeth. A pinion is a gear with a small number of teeth designed to mesh with a larger gear (Figure 4.1.1).

A rack, as a slider, can be imagined as a spur gear having an infinitely large radius with the meshing gear as the pinion (Figure 4.1.2).

\subsection{Chain and sprocket}

When rigid metal link plates are pinned or hooked together forming a flexible connecting member, this is called a metal chain, or just chain for short. It must be used in conjunction with a sprocket to form a wrapping joint when in transmission to form a chain drive.

Depending on the way the chain wraps on the sprockets, the directions of rotational motion are different, as shown in Figures 4.2.1-4.2.2.

\subsection{Cam and follower}

A cam is an irregularly shaped link that serves as a driving member and imparts a prescribed motion to a driven link called a follower. Depending on the type of follower, a cam joint provides reciprocating rotational or translational motion, as shown in Figure 4.3. 


\subsection{Eccentric pin and swing rod}

An eccentric pin is a small, slender piece of wood or metal located at the end of a rotating rod, which is used to slide in a sliding rail. A swing rod is a link rotating around a shaft, with the sliding rail at one end of the swing rod (Figure 4.4).

For a pin joint, the swing rod provides reciprocating rotational motion as the eccentric-pin rod rotates.
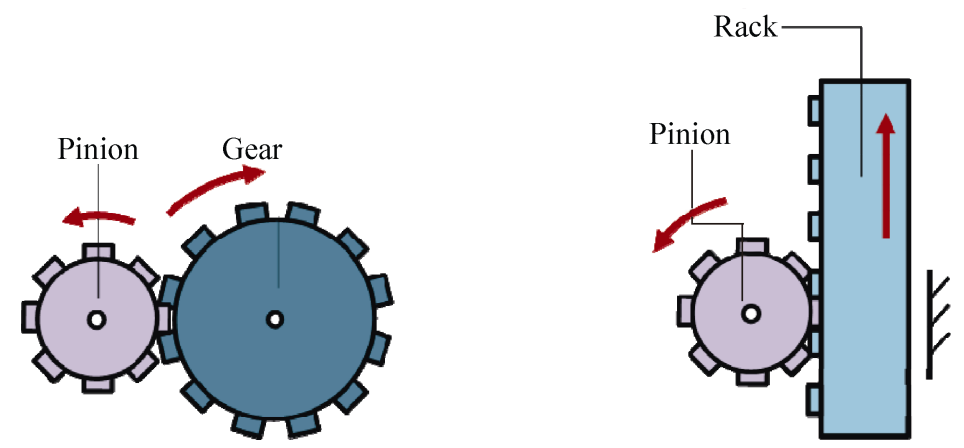

Figure 4: Typical mechanisms and their motions

Figure 4.1.1: Geartrain.

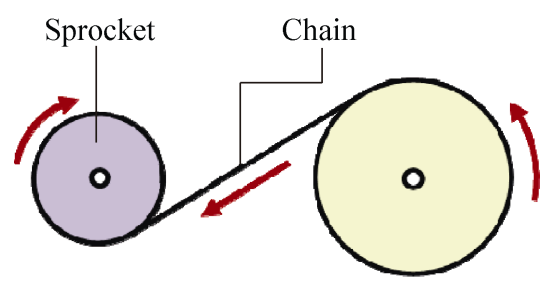

Figure 4.2.1: Chain and sprocket.

Figure 4.1.2: Geartrain.

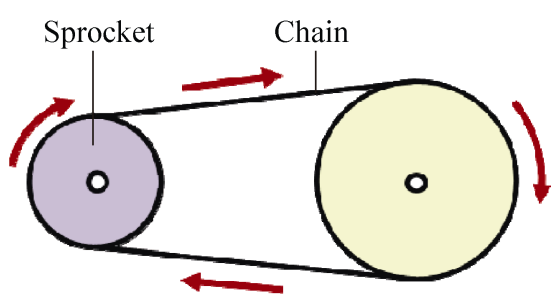

Figure 4.2.2: Chain and sprocket.

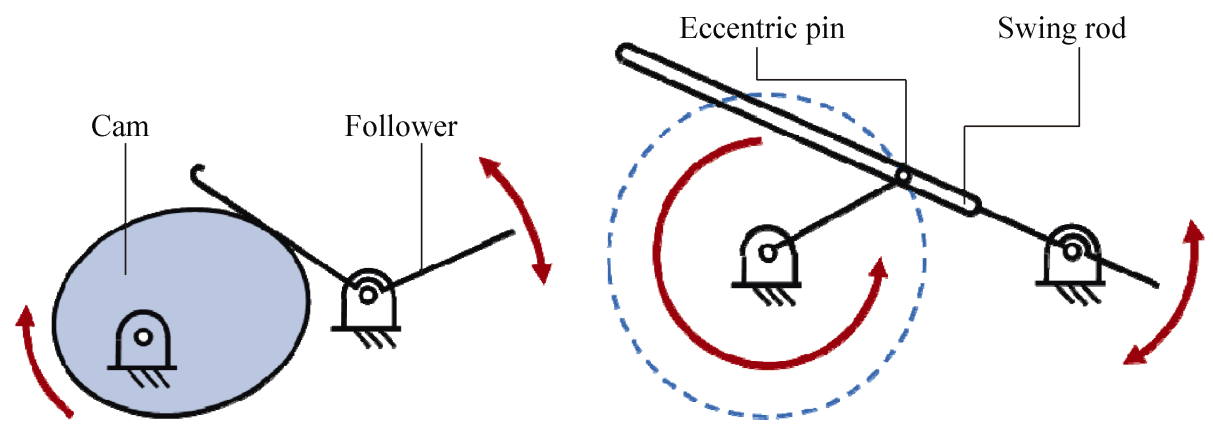

Figure 4.3: Cam and follower.

Figure 4.4: Eccentric pin and swing rod. 
By the eighteenth century, these typical mechanisms were already applied in various machines. In the four pagoda clocks, the automatons are designed according to the combination of these basic mechanisms.

\section{Feasible mechanisms of the pagoda automatons}

Analysis of the descriptions in the literature (Guan 2007; Yun and Qin 2003; Lang and Qin 2002; Qin 2007) shows that a pagoda automaton is driven by two mechanisms: a controlling mechanism and a lifting mechanism (Figure 5). The controlling mechanism's input is a continuous rotation from the clockwork spring, and the motion is transmitted into an oscillating rotation through the mechanism. In other words, a component (typically a gear) is serving as the output part with the motion of clockwise or counterclockwise rotation alternately. The lifting mechanism's input is the oscillating rotation from the controlling mechanism, and the motion is transmitted into a linear reciprocated motion. That is to say, a component is serving as the output part with a motion of sliding upward and downward to lift and return the pagoda, respectively. The motions of these two mechanisms are closely related to each other. For example, when the output component of the controlling mechanism rotates clockwise, the lifting mechanism moves upwards, and vice versa.
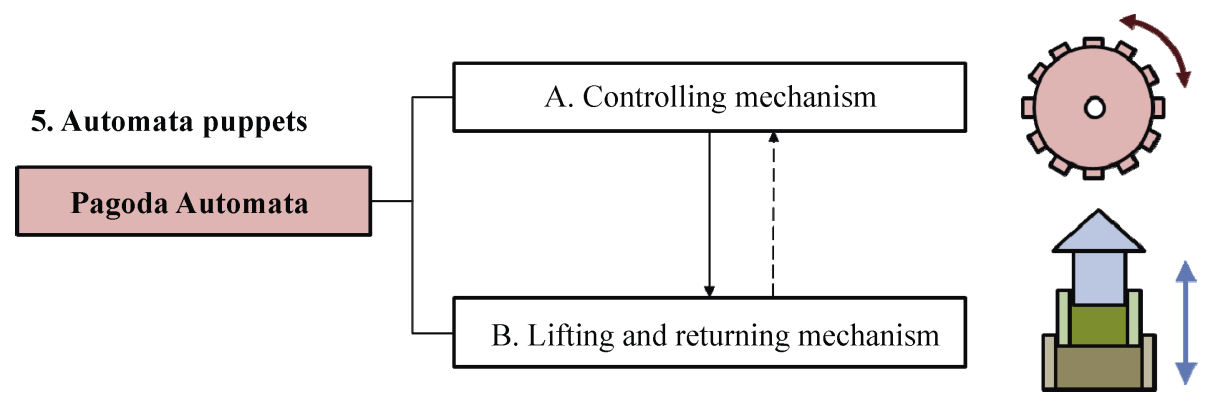

Figure 5: Power flow of a pagoda automaton.

\subsection{Controlling mechanisms}

In order to switch the motion directions of the pagoda, the controlling mechanism is installed to generate an oscillating rotation. The feasible mechanism structure can be arranged and explained with illustrations as described in Guan (2007), Yun and Qin (2003), Lang and Qin (2002), and Qin (2007).

\subsubsection{Guard pagoda clock}

The guard pagoda clock (Figure 1.1) was made in Britain in the eighteenth century. Its 
pagoda has five stories above the pedestal of the clock. The total weight of the top four stories and the ball at the top of the tower is $5.25 \mathrm{~kg}$ (Yun and Qin 2003). It has a clock dial on each of three sides on the pedestal, with needles indicating the time simultaneously.

Eaves of the pagoda are hung with bells, and stones are inlaid to cover the tower. There are four automatic guards standing at each of the four corners of the pedestal. The clock is also decorated with honor-guard, water, and flower automatons (Qin 2007).

When the machine is wound up and started, the music box plays pleasant Chinese folk music (Lang and Qin 2002). The top four stories of the pagoda rise up gradually one by one (Guan 2007), and the bells also jingle to the sound of music (Yun and Qin 2003). The honor guards march along the platform of the pedestal (Guan 2007). The four-corner guards (Qin 2007), and the water and flower automatons, also rotate at the same time (Guan 2007). When the pagoda's stories rise to a certain height or when the tower rises by $27.5 \mathrm{~cm}$ (Yun and Qin 2003), the motion of the automatons pauses and the music also stops (Guan 2007).

When the machine starts up again or at the next hour (Lang and Qin 2002), the music resumes and the pagoda descends to its lowest position, story by story (Guan 2007). At the end of the music, the pagoda eaves overlap with the eaves of the fifth story (Lang and Qin 2002). Meanwhile, the water, flower, and honor-guard automatons stop running, and the music also stops (Yun and Qin 2003). All the independent automatons are connected with each other to run according to a fixed mechanical program (Qin 2007).

Two sets of devices, both powered by springs, comprise the clock mechanism (Figure 6). One set of devices is used to realize timing and telling time, and the other is used to realize music-playing and the vertical movement of the pagoda. The corresponding schematic diagram of the pagoda movement is shown in Figure 7. In the music-playing part, a ratchet roller gear is engaged and driven by the transmission gear to push the hammer to play the music (Yun and Qin 2003).

The vertical movement of the pagoda is controlled by a rack that is set at the top of the pagoda. One side of the rack is engaged with a pinion wound with a chain. The chain is controlled by the rotation of the transmission gear.

When the transmission gear is driven by the clockwork spring and rotates, the chain is pulled to drive the pinion to rotate. In doing so, the rack meshing with this pinion rises upwards and pushes the pagoda's stories up. The pagoda's lowering motion is driven by its weight.

In order to solve the problem of falling speed being too fast, there is one more clockwork spring arranged to connect with the chain. When the pagoda stories move downwards, this spring is wound up and provides a reaction force; when the pagoda stories rise up, this spring works with the main clockwork spring to supply a resultant force (Yun and Qin 2003). 

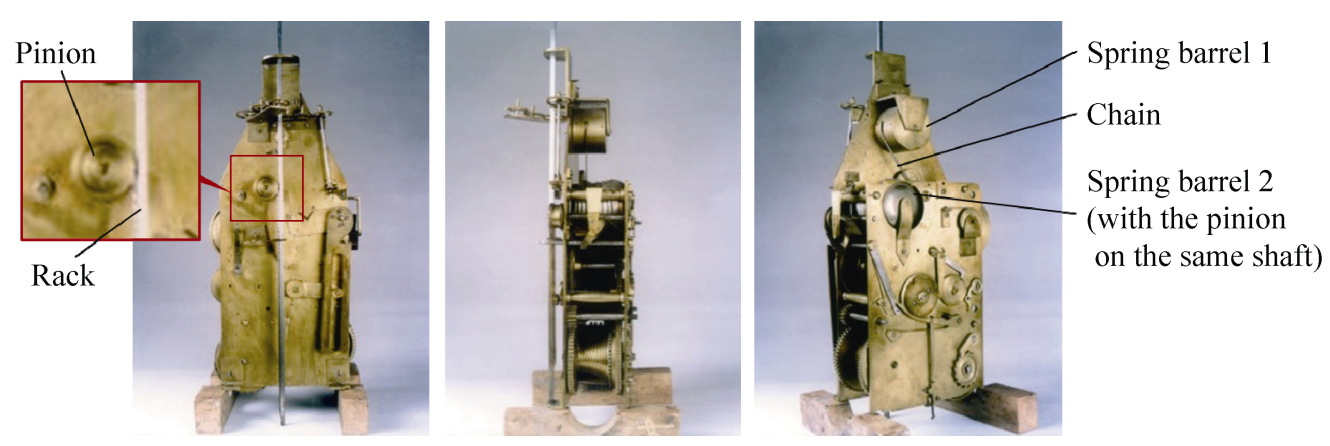

Figure 6: Internal mechanism structure of the guard pagoda clock (Qin 2007).

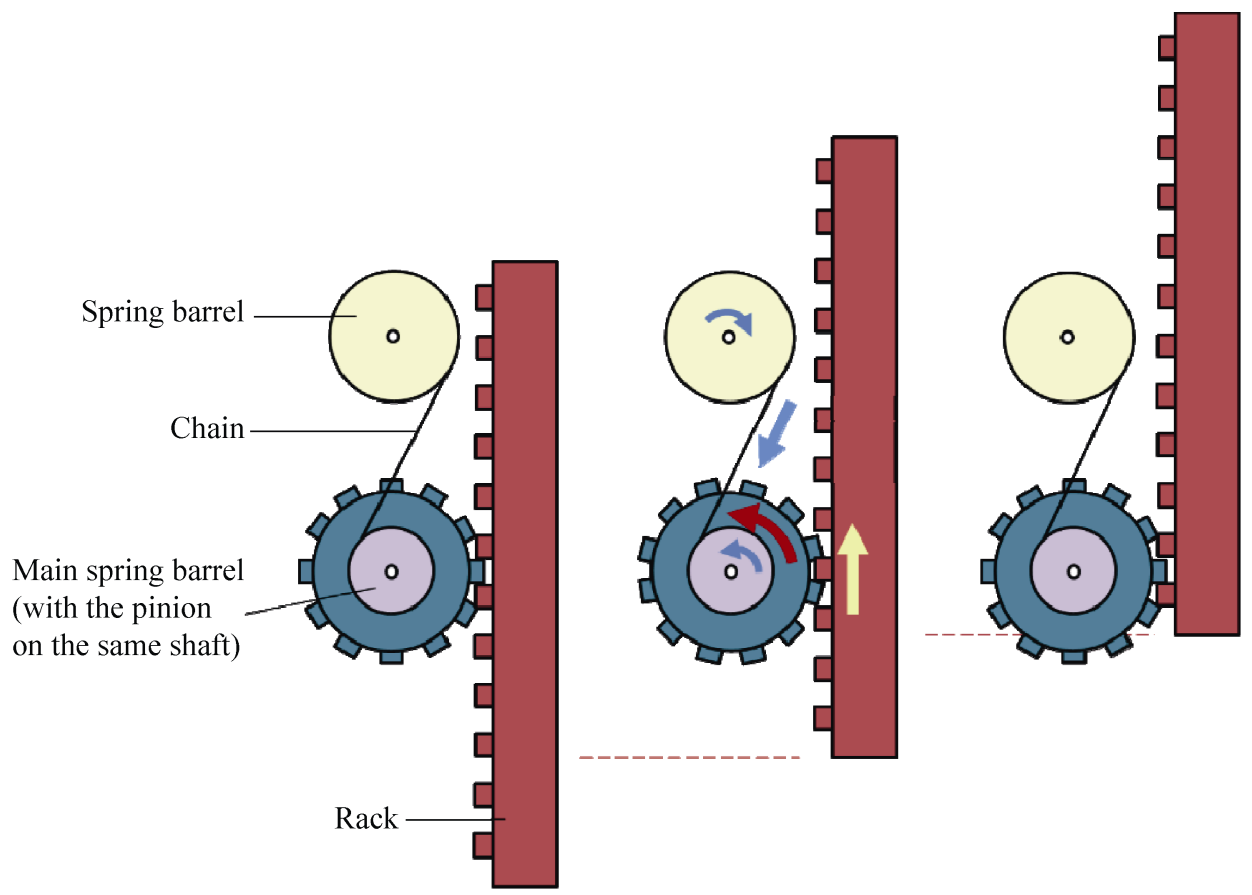

Figure 7: A raising and returning device with rack and pinion.

\subsubsection{Cock pagoda clock}

The cock pagoda clock (Figure 1.2) was made in England in the eighteenth century. This is one of the high-quality clocks made by James Cox. It is $244 \mathrm{~cm}$ high, $102 \mathrm{~cm}$ wide, and $90 \mathrm{~cm}$ deep, and consists of a pedestal and a body. The pedestal is a pavilion with four pillars of lush palm trees, and a gold-plated bronze cock stands inside. The clock body is a garret with a pagoda which is built on rocks, and the pagoda on the top can rise and fall. A glass mirror is laid under the rocks to show the surface of the water. Screwed glass tubes (water automatons) between the rocks represent waterfalls.

There is a small clock with two needles inlaid in the front of the garret. A 
magnifying glass in the back door of the garret is used to see the garden inside and the waterfalls between the rocks.

The machine used to control the music, waterfall automatons, and the motion of the pagoda is arranged at the bottom of the garret. When the music starts to play, the screwed glass tubes rotate to show a visual effect of waterfalls, and the pagoda's stories rise and fall repeatedly (Guan 2007).

In the transmission gears, a cam at the top is driven by a fixed row of gears (Figure 8). A lever with a chain is connected with the cam, and the other side of the chain is linked with a square pole (Lang and Qin 2002). When the cam rotates by gear transmission, the square pole performs vertical movement for the pagoda outside to follow.
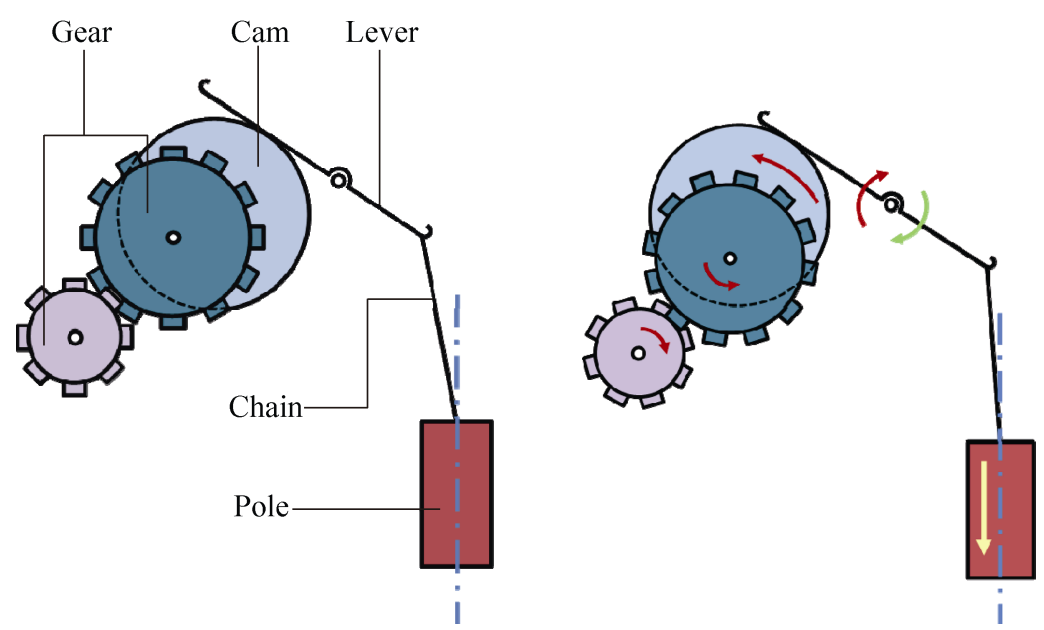

Figure 8: A feasible mechanism for the cock pagoda clock.

Figure 8.1: Initial position.

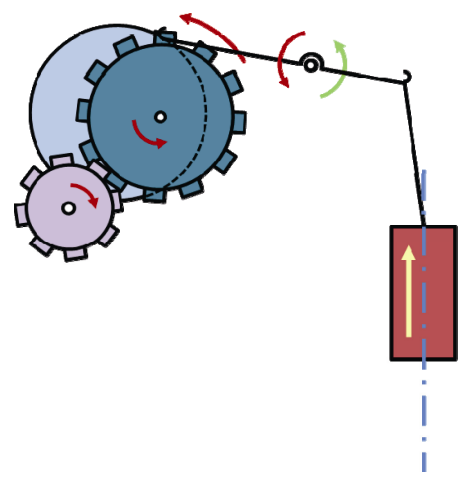

Figure 8.2.2: The follower rotates clockwise as the lifting-up mode.
Figure 8.2.1: The follower rotates clockwise as the lifting-up mode.

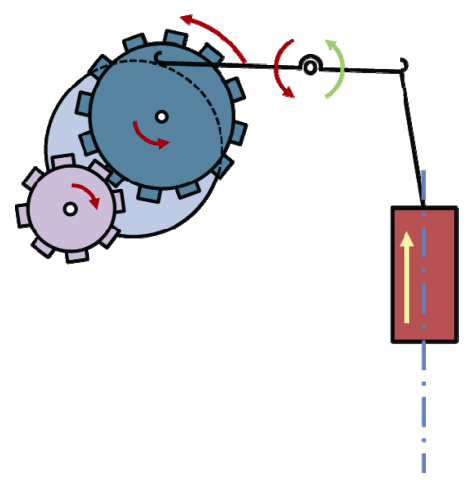

Figure 8.3: The follower rotates counterclockwise as the returning mode. 


\subsubsection{Movable pagoda clock}

The movable pagoda clock (Figure 1.3) is a clock with a seven-story octagonal pagoda resting on a pedestal (Lang and Qin 2002). With a clock dial inlaid on the side and four automaton puppets standing on it, the pedestal is hollow to contain all the movements. When the clockwork spring behind the pedestal is wound up, the automatons start up, with musical accompaniment (Guan 2007). The top five stories of the pagoda gradually lift up, one by one (Guan 2007), and the four puppets bow in to worship (Lang and Qin 2002). When the pagoda rises to the top, it stays for a moment, and then it returns sequentially from the bottom story. Finally, all stories return to their initial positions, the music stops and the puppets return to a standing posture (Guan 2007). There are two sets of movements. One is for the timing and striking systems, the other is used on the music box and the automatons. These two movements are powered by the clockwork springs. When the movements are activated, the transmission gears drive the ratchet roller to rotate, so that the bell clappers strike to play music (Yun and Qin 2003). In the meantime, power is transferred through the control system to adjust the motion of the automatons.

In the transmission system shown in Figure 9, a gear with an eccentric pin drives a swing rod, and a fan-shaped gear rotates in a reciprocating motion. The fan-shaped gear is engaged with the other gear, on which a chain is wound. When the fan-shaped gear rotates in a reciprocating motion, the chained gear rotates clockwise and then counterclockwise (Yun and Qin 2003). During clockwise rotation, the chain is rolled up and a square pole connected with the chain is lifted. The square pole supports the pagoda to rise up from the top story. When the gear rotates counterclockwise, the chain is lowered and the square pole also moves down under the weight of the pagoda's stories until they return to their initial positions (Yun and Qin 2003).
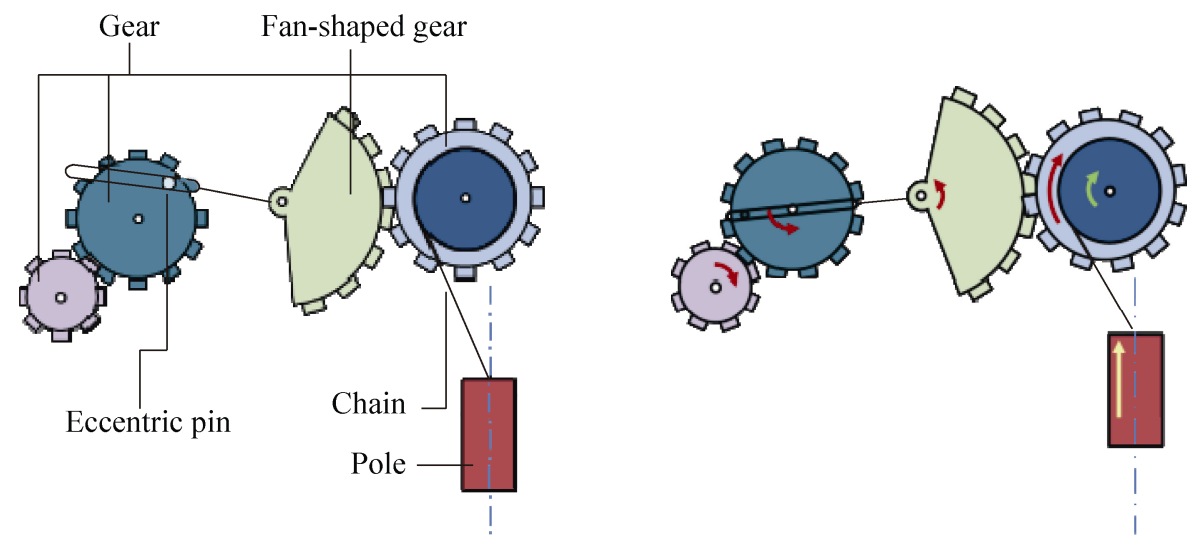

Figure 9: A feasible mechanism for the movable pagoda clock.

Figure 9.1: Initial position.

Figure 9.2.1: Clockwise rotation for lifting up. 


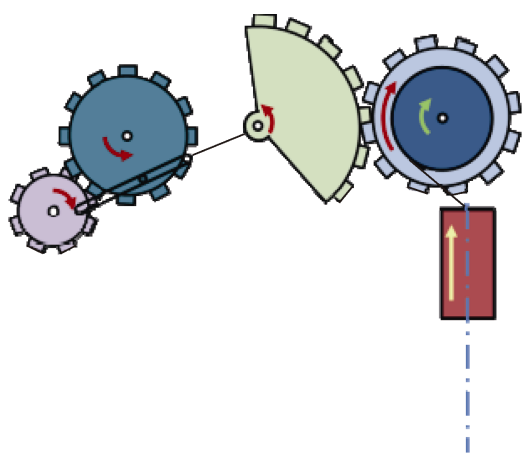

Figure 9.2.2: Clockwise rotation for lifting up.

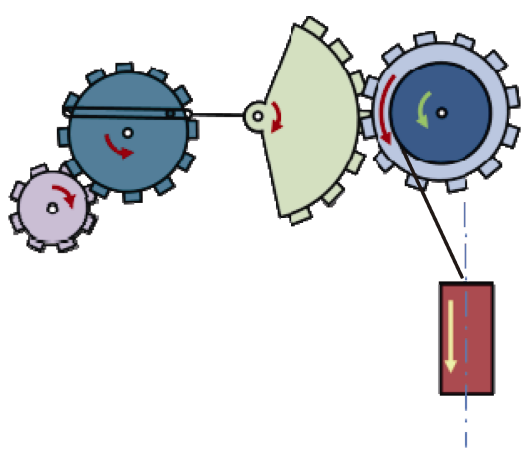

Figure 9.3: Counterclockwise rotation for returning.

\subsubsection{Inlaid enamel longevity clock}

The inlaid enamel longevity clock (Figure 1.4) was made in Guangzhou, China. It is 108 $\mathrm{cm}$ high, $45 \mathrm{~cm}$ wide, and $38 \mathrm{~cm}$ deep, and has three stories. Music and automaton devices are installed in the first story. In the center of the front, there is a clock with three needles. In the arches located on both sides of the clock, there are double rotatable boys holding flower baskets, and the left and right sides of the box are covered with screwed glass rods. Inside the door of the second story, there is a nine-story gilded copper Buddhist pagoda which can rise and fall. On each side of the pagoda, there is an immortal with wings, praying with both palms pressed together (Lang and Qin 2002). The third story is a pavilion, with a figure holding a folding notebook inside. The four corners of the second and third stories are decorated with rotatable flowers.

The clock is wound up behind the first story, and when the music plays the boys holding baskets rotate. The Buddhist pagoda in the middle gradually rises and the winged immortal prostrates himself in prayer (Lang and Qin 2002). The figure holding the folding notebook moves out of the pavilion, opens the notebook, and writes in it four Chinese characters: qian qiu yong gu 千秋永固 (immortal dynasty). Meanwhile, the flowers rotate at the four corners. When the music stops, all the automatons stop (Lang and Qin 2002).

Similar to the first clock, an eccentric pin on a transmission gear drives the reciprocating rotations of a swing rod (Figure 10), with the difference that the other end of the swing rod is directly linked to the pole (Yun and Qin 2003). Thus the vertical movement of the pole is realized by the reciprocating rotations of the rod, and the movement of the pagoda follows the motion of the pole. 


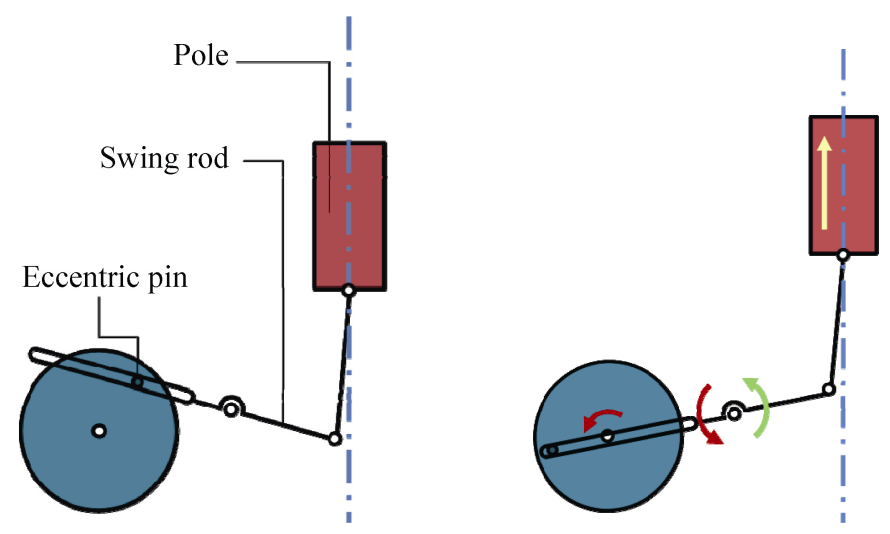

Figure 10: A feasible mechanism for the inlaid enamel longevity clock.

Figure 10.1: Initial position.

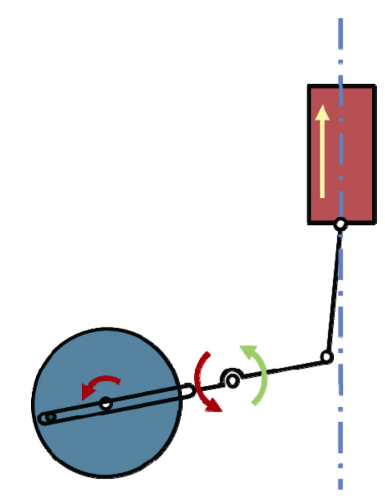

Figure 10.2.2: The middle link rotates clockwise as the lifting-up mode.
Figure 10.2.1: The middle link rotates clockwise as the lifting-up mode.

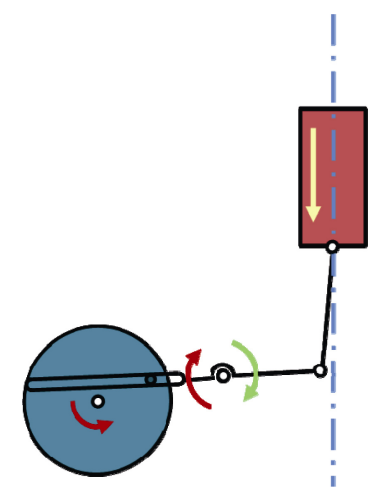

Figure 10.3: The middle link rotates counterclockwise as the returning mode.

\subsection{Lifting and returning mechanisms}

According to the descriptions in Yun and Qin (2003) and Qin (2007), the lifting mechanisms of the pagoda automatons are transmitted by the chains. The mechanical structure of the guard pagoda clock (Figure 1.1) has been published with photos (Figure 6). However, this mechanism is different from the records of the other pagoda automatons, and their mechanical structures are not clear because of the limited text descriptions. Therefore the lifting system of the mechanism shown in Figure 6 is explained below, and two feasible mechanisms that are able to match the descriptions are provided. 


\subsubsection{Rack-and-pinion transmission}

The photos published by the technicians at the clock workshop in the Beijing Palace Museum are shown in Figure 6. A rack-and-pinion mechanism with two spring barrels and a chain can be seen, and the corresponding schematic diagrams are presented in Figure 7. A spring barrel rotates clockwise and causes the pinion to rotate counterclockwise, driven by the spring barrel through a chain between them. The rack, which is confined to a track, can only move up and down to mesh with the pinion. Thus the rack driven by the spring barrel moves upwards and transmits force to the movement through the gear and the chain, and the force can therefore lift the payloads as the spring releases energy. In the opposite case, when the energy of the spring is used up, there is not enough force to support the payloads. At this moment, the rack begins to fall and returns to its original position under its own weight and that of the payloads. In this process the payloads do work to the spring through the transmission mechanisms, and the spring can be rewound to a certain extent.

\subsubsection{Chain-and-sprocket transmission}

Two lifting and returning devices with a chain and sprocket are shown in Figure 10. In the device in Figure 11.1, one end of the chains is wound around the driving wheel, which is arranged in the middle of the fixed frame. The other end of the chains is connected with the pin fixed on the outer movable frame. The chain in turn passes the fixed sprocket on the fixed frame and two relatively stationary movable sprockets on the middle movable frame. When the driving wheel rotates and the chains are wound around it, the distances between the fixed sprocket and the movable sprocket, and between the pin and the second movable sprocket, are shortened. As a result, the movable frames with payloads are lifted up under the action of chain tension. When the driving wheel rotates in the opposite direction, the chains are released, and the frames are lowered by gravity and return to their original position. With a similar approach, more layers of frames can be raised and lowered simultaneously.

In the device in Figure 11.2, there are two driving wheels arranged at the left and right ends of the fixed frame. The two driving wheels synchronously control a chain to realize the lifting and returning of a pole. The two ends of the chain are connected to both sides of the top of the pole. Four fixed sprockets, which make the pole move up and down only, are arranged on the fixed frame, and one movable sprocket is arranged on the pole. The chain passes through the left upper fixed sprocket, the left driving wheel, the left lower fixed sprocket, the movable sprocket, the right lower fixed sprocket, the right driving wheel, and the right upper fixed sprocket in turn. When the left wheel rotates clockwise and the right wheel counterclockwise, the distance between the movable sprocket and the fixed sprocket decreases, while the distance between the 
fixed sprocket and the top of the pole increases, so that the pole is lifted. In the opposite case, the distance between the fixed sprocket and the top of the pole decreases, causing the pole to drop and return to its original position.

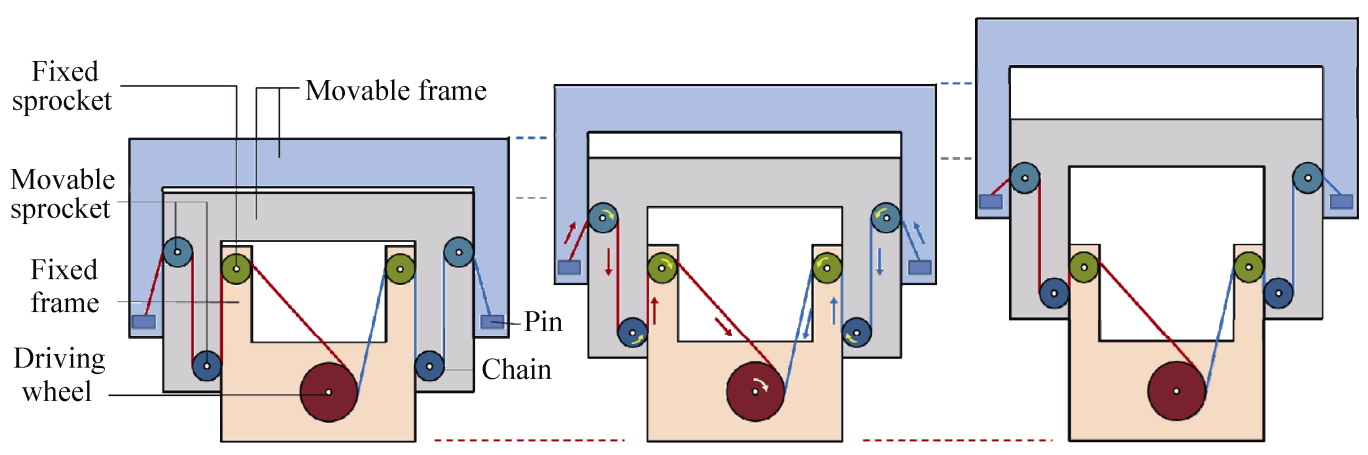

Figure 11: Two types of raising and returning devices with chain-and-sprocket mechanisms.

Figure 11.1: The raising and returning devices with multi-level.

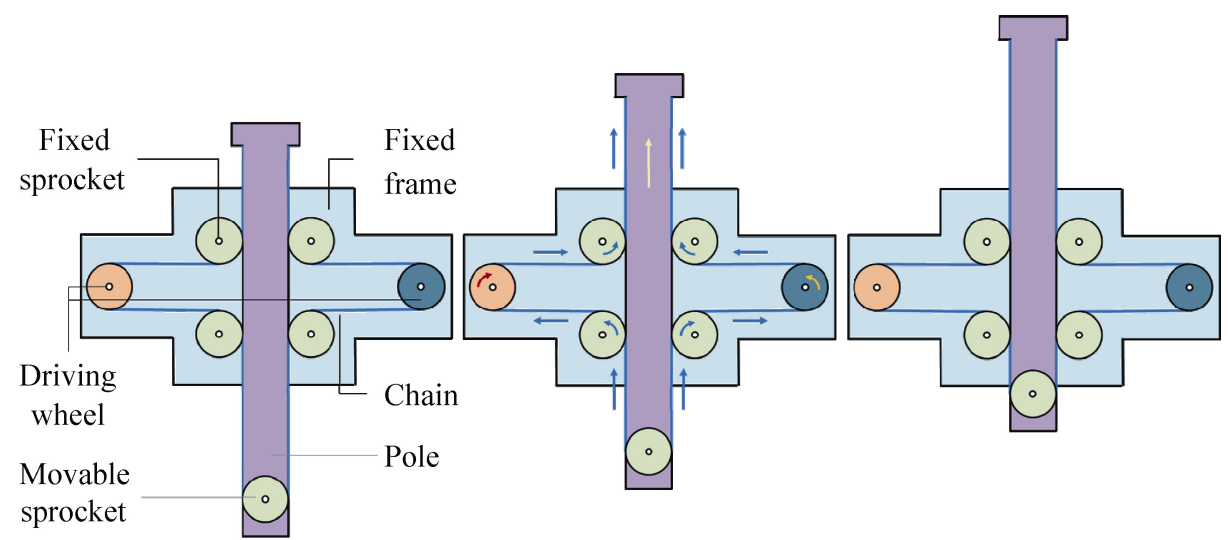

Figure 11.2: The raising and returning devices with single-level.

\section{Conclusions}

This study introduces four clocks with pagoda automatons made in the eighteenth century and now preserved in the Beijing Palace Museum. The historical background of the clocks is described, and the pagoda automatons are introduced with their basic information. Five subsystems - namely power source, transmission, timekeeping device, music generator, and automaton puppets - are analyzed. Their most obvious subsystem, the pagoda automaton, is taken to illustrate the feasible mechanisms. The controlling and lifting mechanisms inside the pagoda are also analyzed. In accordance with the available literature (Guan 2007; Yun and Qin 2003; Lang and Qin 2002; Qin 2007), some feasible 
mechanism structures are proposed. The motion direction of the pagoda automatons is generated by controlling devices with various translated mechanisms to achieve the oscillated rotation output. The lifting-up and returning motions are mainly driven by the chain-and-sprocket mechanism. As a result, four different mechanisms are applied to the four pagoda automatons to translate the oscillated rotation from the controlling mechanism. Linkage, gear, cam, and/or chain mechanisms are also applied in these clocks with different arrangements for the controlling mechanism.

These four ancient clocks reflect the level of manufacturing technology in the eighteenth century, and they are also evidence of exchanges between Britain and China in the area of culture, science, and technology. Furthermore, this study offers a mechanical design consideration for reconstructing ancient automatons with unclear mechanisms, which also provides a different lens for understanding ancient automatons.

\section{Acknowledgments}

The authors are grateful to the collaborative research program between the Science Museum in London, Beijing Jiaotong University, and the Institute for the History of Natural Sciences (Chinese Academy of Sciences) on "Time, Culture and Identity: The Co-Creation of Historical Research and Co-Development of Visitor Experience in China and the UK" supported by the UK's Arts and Humanities Research Council.

\section{References}

Aisin Gioro, Xuanye (Emperor Kangxi) 爱新觉罗・玄烨（康熙帝）. 1711. “Yong zimingzhong” 咏自鸣钟 [Chant of the Chime Clocks]. In Shengzuren Huangdi yuzhi wen siji 圣祖仁皇帝御制文 四集 [Imperially Authored Essays of Emperor Shengzuren Collection Four]. Vol. 1299, juan 32 of Jingyin Wenyuange Siku Quanshu 景印文波阁四库全书 [Photofacsimile Reprint of the Wenyuan Pavilion Copy of Complete Collection in Four Treasuries].

Andrewes, W. J. H. 2002. "A Chronicle of Timekeeping." Scientific American 287 (3): 76-85.

Chen, Yu-Hsun, and Yan Hong-Sen. 2016. "Reconstruction of Unknown Automata Designs of Blossoming Flower Clock in Forbidden City." Proceedings of the Institution of Mechanical Engineers, Part C: Journal of Mechanical Engineering Science 231 (7): 1354-1368.

Chen, Yu-Hsun, Marco Ceccarelli, and Yan Hong-Sen. 2017a. "Designing and prototyping reconstruction of musician automata." In New Activities for Cultural Heritage: Proceedings of the International Conference Heritagebot, edited by Marco Ceccarelli, Michela Cigola, and Giuseppe Recinto, 22-32. Cham: Springer.

Chen, Yu-Hsun, Marco Ceccarelli, and Yan Hong-Sen. 2017b. "Performance Analysis of the Automata in a Blossoming Flower Clock in the 18th Century." In Advances in Service and Industrial Robotics, edited by C. Ferraresi and G. Quaglia, 1017-1024. Cham: Springer.

Chen, Yu-Hsun, Marco Ceccarelli, and Yan Hong-Sen. 2018. "A Historical Study and Mechanical Classification of Ancient Music-Playing Automata." Mechanism and Machine Theory 121:273-285. Chen, Zuwei 陈祖维. 1984. “Ouzhou jixiezhong de chuanru he Zhongguo jindai zhongbiaoye de 
fazhan”欧洲机械钟的传入和中国近代钟表业的发展 [The Introduction of the Mechanical Clock from Europe and Development of the Modern Timepiece Industry in China]. Zhongguo keji shiliao 中国科技史料 [China Historical Materials of Science and Technology] 12 (1): 179183.

Dai, Nianzu 戴念祖. 2004. “Zhongguo jindai jixie jishiqi de zaoqi fazhan” 中国近代机械计时器的 早期发展 [Early Development of the Modern Mechanical Timer in China]. Zhongguo jiliang 中 国计量 [China Metrology] (2): 43-45, 48.

Guan, Xueling 关雪玲. 2007. Ni yinggai zhidao de 200 jian zhongbiao 你应该知道的 200 件钟表 [200 Timepieces You should Know]. Taipei: Artist Publishing.

Guo, Fuxiang 郭福祥. 2013. Shijian de lishi yingxiang: Zhongguo zhongbiaoshi lunji 时间的历史映 像: 中国钟表史论集 [Historical Images of Time: Essays on the History of Chinese clocks]. Beijing: The Forbidden City Publishing House.

Hou, Hao-Chih 侯皓之. 2011. “Xishou yu chuangxin: Shengqing zhudi dui Xiyang gongyi de zhidao yu chuangzhi” 吸收与创新一一盛清诸帝对西洋工艺的指导与创制 [Absorption and Innovation: How Emperors of High Qing Dynasty Shape the Western Craftsmanship]. Shixue huikan 史学汇刊 [Journal of the Historical Studies] 28 (12): 111-154.

Lang, Xiuhua 郎秀华, and Qin Xiaopei 秦晓培. 2002. Qinggong zhongbiao jicui: Beijing Gugong zhencang 清宫钟表集粹: 北京故宫珍藏 [Clocks and Watches of the Qing Dynasty: From the Collection in the Forbidden City]. Beijing: Foreign Languages Press.

Li, Youru 李侑儒. 2009. Ming Qing de zhongbiao (1582-1911) 明清的钟表（1582 1911） [Clocks and Watches in Ming-Ching Period (1582-1911)]. Master's thesis, NCCU.

Pagani, C. 2001. Eastern Magnificence and European Ingenuity: Clocks of Late Imperial China. Ann Arbor: University of Michigan Press.

Qin, Shiming 秦世明. 2007. “Gugong Bowuyuan cang zhongbiao xiufu juyao” 故宫博物院藏钟表 修复举要 [Restoration of Clocks in the Palace Museum]. Zijincheng 紫禁城 [Forbidden City] (7): 112-121.

Rocci, Cesare, Flavio Russo, and Ferruccio Russo. 2009. "Automata (Towards Automation and Robots)." In Ancient Engineers' Inventions, 269-301. Dordrecht: Springer.

Wang, Jin 王津, Qin Shiming, and Qi Haonan 元昊楠. 2008. “Qingdai yuzhi zhongbiao tanwei” 清代御制钟表探微 [Exploration of the Imperial Clock Workshop in the Qing Dynasty]. Zhongguo lishi wenwu 中国历史文物 [Journal of National Museum of China] (2): 34-42, 94-96.

Xu, Chaojun 徐朝俊. 1809. Ziming zhongbiao tufa 自鸣钟表图法 [Illustrated Description of Chime Clocks and Watches]. In Gao hou meng qiu 高厚蒙求.

Yan, Hong-Sen. 2016. Mechanisms: Theory and Applications. New York: McGraw-Hill.

Yun, Limei 恽丽梅, and Qin Shiming. 2003. Yang gudong: Zhongbiao 洋古董: 钟表 [Foreign Antiques: Clocks and Watches]. Beijing: Beijing Publishing Group.

Zhang, Baichun 张柏春. 1995. “Ming Qing shiqi Ouzhou jixie zhongbiao jishu de chuanru ji youguan wenti” 明清时期欧洲机械钟表技术的传入及有关问题 [The Importation of European Clock and Water Technology into China and the Questions concerned during the late Ming and Qing Dynasties]. Ziran bianzhengfa tongxun 自然辩证法通讯 [Journal of Dialectics of Nature] 17 (2): 185-193. 